\title{
PRODUÇÃO DE MUDAS DE EUCALIPTO EM DIFERENTES COMPOSIÇÕES DE SUBSTRATOS
}

\author{
Cristiane Ramos Vieira ${ }^{1}$ e Oscarlina Lúcia dos Santos Weber ${ }^{2}$
}

\begin{abstract}
Resumo: $A$ produção de mudas de qualidade requer a utilização de técnicas e insumos que sejam compatíveis com os requerimentos da espécie produzida. Diante disso, realizou-se experimento em viveiro com o objetivo de verificar a combinação de solo, substrato comercial (Plantmax®) e cama de frango decomposta, mais propícia para a produção de mudas de Eucalyptus camaldulensis. As mudas foram produzidas em tubetes com capacidade de $160 \mathrm{~cm}^{3} \mathrm{com}$ sementes colocadas para germinar em areia e vermiculita. Ao atingirem $15 \mathrm{~cm}$, as plantas foram transplantadas para os tratamentos: 100\% solo; $100 \%$

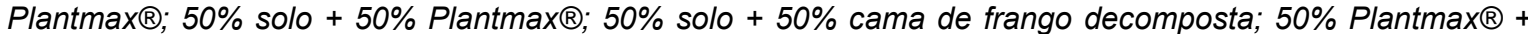
$50 \%$ cama de frango decomposta; $80 \%$ cama de frango decomposta $+10 \%$ solo $+10 \%$ Plantmax e e $20 \%$ cama de frango decomposta $+40 \%$ solo $+40 \%$ Plantmax $®$, originando sete tratamentos, em delineamento inteiramente casualizado, com 10 repetições. A avaliação do crescimento se deu com a medição de altura da parte aérea, diâmetro de colo, biomassa das folhas, biomassa do caule e biomassa das raízes e, concentrações de nutrientes. A combinação de substratos que proporcionou o maior crescimento das mudas de Eucalyptus camaldulensis foi 50\% Plantmax ${ }^{\circledR}+50 \%$ cama de frango decomposta.
\end{abstract}

Palavras-chave: Eucalyptus camaldulensis. Insumo orgânico. Matéria orgânica. Substrato orgânico.

\section{Introdução}

Eucalyptus camaldulensis Dehn é uma espécie florestal nativa da Austrália e bastante utilizada em plantios comerciais no Brasil devido sua rusticidade e adaptabilidade às condições de baixa fertilidade (FERREIRA, 1979). De acordo com Del Quiqui, Martins e Shimizu (2001) apresenta ampla distribuição geográfica e pode ocupar diversos ambientes ecológicos, é tolerante a inundações temporárias e resistente a temperaturas elevadas. Segundo esses autores, a espécie pode ser indicada para zonas críticas, onde as deficiências hídricas e problemas ligados ao solo sejam fatores limitantes. A madeira de $E$. camaldulensis é de cor avermelhada e densidade similar a do Eucalyptus cloeziana, dura, muito durável e resistente aos cupins, apta para dormentes, construções pesadas, óleo essencial, marcenaria, tanino, carvão (MORAES NETO, 2008) e na indústria moveleira (SOUZA et al., 2009).

Essas características condicionam o E. camaldulensis para o plantio em solos típicos de Cerrado. Porém, antes de proceder com o seu plantio, há que se produzir muda de qualidade (SILVA et al., 2011, SILVA et al., 2014) e, isso implica no conhecimento, tanto dos requerimentos nutricionais da espécie (OLIVEIRA et al., 2014), quanto dos nutrientes disponibilizados pelo substrato (TUCCl et al., 2011). Porque, durante a produção das mudas, o substrato será utilizado para promover a sustentação do porte das plantas, bem como a sua nutrição.

Portanto, um dos procedimentos que influenciam no crescimento das mudas e na sua qualidade, é a composição do substrato (OLIVEIRA et al., 2014; TRAZZI, DELARMELINA; CALDEIRA, 2014), cujas características físicas e químicas devem ser compatíveis com aquelas requeridas pela espécie que se pretende produzir. Isso ocorre em função da necessidade de desenvolver estudos que objetivem conhecer técnicas, proporções e combinações de substratos que sejam menos onerosos.

A utilização de substrato comercial é uma das alternativas para a produção das mudas em viveiros. Kratz et al. (2013) verificaram que o substrato comercial a base de casca de pinus semidecomposta foi adequado para a produção de mudas de Mimosa scabrella. Porém, a utilização desses substratos implica em gastos financeiros. Além disso, nem sempre eles fornecem quantidades satisfatórias de 


\section{REA - Revista de estudos ambientais (Online) v.18, n. 2, p.25-34, jul./dez. 2016}

nutrientes, precisando ser enriquecidos com fertilizantes (SCHEER; CARNEIRO; SANTOS, 2010). Uma das formas de desonerar o processo, então, é a utilização de resíduos orgânicos, que podem promover melhorias químicas e físicas que irão assegurar a formação de mudas de melhor qualidade.

Segundo Brugnara (2014) a utilização de adubo orgânico na produção de mudas, além de ser aceita em sistemas produtivos agroecológicos ou orgânicos, reduz o custo de produção por ser mais barato que fertilizantes minerais sintéticos e substratos comerciais. A cama de frango curtida é um dos produtos orgânicos utilizados na produção de mudas de espécies florestais. De acordo com Weinärtner, Aldrigh e Medeiros (2006) esse material quando bem curtido, apresenta-se bem farelado, escuro e frio, muito rico em $\mathrm{N}$.

Várias combinações de substratos estão sendo testadas pelos pesquisadores e, pelos resultados obtidos verifica-se que essas dependerão da espécie a ser produzida bem como dos tipos de componentes. Silva et al. (2014) testando substratos orgânicos na produção de mudas de Eucalyptus grandis constataram que o composto orgânico de lixo urbano e o composto orgânico de resíduo agroindustrial apresentaram grande potencialidade de uso como substratos alternativos para a espécie. Para o Eucalyptus dunnii o substrato formado por casca de arroz carbonizada e vermiculita fina na proporção de $50 \%$ de cada, foram os mais indicados por Kratz e Wendling (2013). Enquanto que, as mudas de Tectona grandis produzidas com substratos formulados com cama de frango apresentaram maiores ganhos biométricos, sendo que a proporção de $35 \%$ foi o tratamento que resultou nos maiores índices das características analisadas (TRAZZI; DELARMELINA; CALDEIRA, 2013).

Diante disso, 0 objetivo do experimento foi avaliar as diferentes combinações e proporções de componentes (solo, Plantmax ${ }^{\circledR}$ e cama de frango decomposta) no crescimento inicial e na nutrição de mudas de E. camaldulensis.

\section{Material e métodos}

O experimento foi instalado na casa de vegetação da Faculdade de Agronomia,
Medicina Veterinária e Zootecnica (FAMEVZ) da Universidade Federal de Mato Grosso (UFMT), em Cuiabá, construída de material telado tipo sombrite branco e coberta com telha de amianto, sem controle de temperatura. $\mathrm{E}$ foi realizado no período de julho a outubro de 2015.

As sementes de E. camaldulensis foram coletadas de 20 árvores matrizes espaçadas em $100 \mathrm{~m}$, em plantio localizado no município de Dom Aquino-MT. Essas sementes foram colocadas para germinar em tubetes com capacidade de $160 \mathrm{~cm}^{3}$, preenchidos com areia lavada e vermiculita, sendo colocadas quatro a cinco sementes por tubete, dentro da casa de vegetação. Após a germinação e atingirem $5 \mathrm{~cm}$ de altura (30 dias após a semeadura) foi realizado o raleamento para deixar apenas uma planta por tubete. Ao atingirem $15 \mathrm{~cm}$ (25 dias após o raleamento), as plantas foram transplantadas para os tubetes preenchidos com as combinações de substratos utilizadas no experimento.

Para a composição dos substratos utilizou-se o solo, classificado como cambissolo húmico textura franco arenosa, coletado da camada de $20 \mathrm{~cm}$, de área sob vegetação de Cerrado, localizada no Instituto Federal de Mato Grosso em São Vicente, MT. O solo foi seco ao ar livre e peneirado em malha de $2 \mathrm{~mm}$.

O substrato comercial utilizado foi o Plantmax ${ }^{\circledR}$, indicado para produção de mudas de espécies florestais. Segundo o fabricante, em sua composição constam casca de pinus, vermiculita de granulometria fina e superfina e húmus.

O material orgânico foi cama de frango, cuja decomposição foi realizada em local aberto com a utilização de minhocas inoculadas diretamente no material, por 90 dias. O composto foi irrigado em dias alternados, mantendo o controle da luminosidade até a obtenção do material decomposto, que foi colhido e submetido ao peneiramento para separação das minhocas e pesagem.

Os substratos foram combinados nas seguintes proporções: $100 \%$ solo (testemunha); $100 \%$ Plantmax $® ; 50 \%$ solo + $50 \%$ Plantmax $® 50 \%$ solo $+50 \%$ cama de frango decomposta; $50 \%$ Plantmax $®+50 \%$ cama de frango decomposta; $80 \%$ cama de frango decomposta $+10 \%$ solo $+10 \%$ Plantmax $® \quad$ e; $20 \%$ cama de frango decomposta $+40 \%$ solo $+40 \%$ Plantmax $®$. 


\section{REA - Revista de estudos ambientais (Online) v.18, n. 2, p.25-34, jul./dez. 2016}

Estas combinações de substrato originaram sete tratamentos, com 10 repetições, dispostos em delineamento inteiramente casualizado e foram utilizadas para preencher os tubetes de polipropileno ficando incubadas por um período de 20 dias. Os tubetes de propileno tinham formato cônico com estrias, perfurados na extremidade inferior, com capacidade para
$280 \mathrm{~cm}^{3}$,. Esse período foi realizado anteriormente ao transplante das mudas e, durante ele, as combinações foram mantidas na casa de vegetação.

Uma amostra de cada tratamento foi retirada para a realização da análise química, segundo métodos da Embrapa (1997) (Tabela 1).

Tabela 1 - Características químicas dos substratos utilizados na pesquisa

\begin{tabular}{|c|c|c|c|c|c|c|c|}
\hline \multirow{2}{*}{ Trat } & $\mathrm{pH}$ & $\mathrm{H}+\mathrm{Al}$ & Al & $\mathrm{Ca}^{2+}$ & $\mathbf{M g}^{2+}$ & $\mathbf{K}$ & $\mathbf{P}$ \\
\hline & $\mathrm{CaCl}_{2}$ & \multicolumn{4}{|c|}{----------- cmolc.dm³ ----------- } & \multicolumn{2}{|c|}{----- mg.dm³ ----- } \\
\hline T1 & 5,62 & 2,7 & 0,3 & 2,0 & 2,1 & 32,15 & 42,04 \\
\hline $\mathrm{T} 2$ & 5,92 & 6,8 & 0,1 & 8,6 & 6,8 & 22,52 & 62,24 \\
\hline T3 & 5,65 & 4,9 & 0,0 & 7,5 & 2,5 & 22,52 & 23,80 \\
\hline T4 & 6,04 & 2,8 & 0,1 & 5,0 & 5,7 & 36,03 & 124,16 \\
\hline T5 & 6,36 & 3,0 & 0,2 & 8,5 & 2,5 & 27,03 & 113,91 \\
\hline T6 & 6,22 & 3,1 & 0,1 & 6,7 & 7,2 & 36,03 & 125,67 \\
\hline $\mathrm{T} 7$ & 6,45 & 4,0 & 0,2 & 7,9 & 5,7 & 27,03 & 113,20 \\
\hline
\end{tabular}

pH em $\mathrm{CaCl}_{2}$ - relação 1:2,5; $\mathrm{H}+\mathrm{Al}$ - em acetato de cálcio; $\mathrm{Al}, \mathrm{Ca}^{2+}$ e $\mathrm{Mg}^{2+}$ - em $\mathrm{KCl} ; \mathrm{P}$ e $\mathrm{K}$ - em Mehlich.

\begin{tabular}{|c|c|c|c|c|c|c|}
\hline \multirow{2}{*}{ Trat } & SB & $\mathrm{T}(\mathrm{pH} 7,0)$ & $\mathbf{t}$ & $\mathbf{V}$ & $\mathbf{m}$ & \multirow[t]{2}{*}{$\mathbf{N}$} \\
\hline & \multicolumn{3}{|c|}{----- cmolc.dm³ } & \multicolumn{2}{|c|}{----- \% ----- } & \\
\hline T1 & 4,18 & 6,88 & 4,48 & 61 & 6,70 & 6,20 \\
\hline $\mathrm{T} 2$ & 12,46 & 19,26 & 12,56 & 65 & 0,80 & 6,40 \\
\hline T3 & 10,06 & 14,96 & 10,06 & 67 & 0,00 & 4,80 \\
\hline T4 & 10,79 & 13,59 & 10,89 & 79 & 0,92 & 7,80 \\
\hline T5 & 11,07 & 14,07 & 11,27 & 79 & 1,77 & 14,60 \\
\hline T6 & 13,99 & 17,09 & 14,09 & 82 & 0,71 & 10,90 \\
\hline T7 & 13,67 & 17,67 & 13,87 & 77 & 1,44 & 5,90 \\
\hline
\end{tabular}

Onde: SB - soma de bases; $\mathrm{T}$ (pH7,0) - capacidade de troca de cátions a $\mathrm{pH} 7,0$; t efetiva - CTC efetiva; $\mathrm{V} \%$ - saturação por bases, em \%; m\% - saturação por Al, em \%; $\mathrm{N}$ - digestão sulfúrica.

Fonte: Autoras (2016)

Após o transplante, as plantas passaram pelo processo de adaptação de 15 dias e, em seguida, realizou-se 0 acompanhamento do crescimento por 90 dias nos substratos testados, sendo todo 0 procedimento realizado dentro da casa de vegetação desde a germinação até 0 acompanhamento do crescimento das mudas. 


\section{REA - Revista de estudos ambientais (Online) v.18, n. 2, p.25-34, jul./dez. 2016}

Ao término do experimento, realizaram-se as biometrias das características morfológicas: altura $(\mathrm{H})$, em $\mathrm{cm}$, medindo da superfície do substrato até a última folha e diâmetro de colo (DC), em $\mathrm{mm}$, medido com paquímetro digital. Para obtenção da biomassa, as mudas foram retiradas do substrato, seccionadas em folhas, caule e raízes e, em seguida as raízes foram lavadas em água corrente. $\mathrm{O}$ material vegetal foi levado à estufa de circulação forçada de ar a $65^{\circ} \mathrm{C}$ até peso constante. Após secagem, foi pesado em balança analítica com precisão de $0,01 \mathrm{~g}$.

O material seco foi moído em moinho tipo Wiley para determinação das concentrações foliares de nutrientes, após as digestões sulfúrica e nitro-perclórica, seguindo métodos de Malavolta, Vitti e Oliveira (1997): N total por semi-micro Kjeldahl; $P$ por colorimetria do metavanadato; $\mathrm{S}$ por turbidimetria do sulfato de bário; $\mathrm{K}$ fotometria de chama de emissão; $\mathrm{Ca}$ e $\mathrm{Mg}$ por quelatometria com EDTA e; $\mathrm{B}$ por colorimetria da azometina $\mathrm{H}$.
Os dados foram interpretados por meio da análise de variância e a comparação de médias foi realizada pelo método de Tukey ao nível de $5 \%$ de probabilidade de erro utilizando o programa estatístico Assistat 7.6 beta, da UFCG, após constatação da normalidade dos mesmos.

\section{Resultados e discussão}

\subsection{Crescimento das mudas de $E$. camaldulensis}

O crescimento das mudas de $E$. camaldulensis foi influenciado pela combinação de substratos, sendo esta, responsável pelo aumento das médias para as características morfológicas (Tabela 2). Verificou-se, nesse caso que, apenas no crescimento do sistema radicular não se observou diferença entre os tratamentos testados, demonstrando que a influência foi maior para o aumento em biomassa do que para o crescimento da raiz.

Tabela 2 - Crescimento em altura, em diâmetro do colo, crescimento radicular, biomassa das folhas, do caule e da raiz das mudas de $E$. camaldulensis em diferentes combinações de substratos

\begin{tabular}{lllllll}
\hline Tratamento & $\mathbf{H}(\mathbf{c m})$ & DC $(\mathbf{m m})$ & Raiz $\mathbf{( c m})$ & BioFolha $\mathbf{( g )}$ & BioCaule $(\mathbf{g})$ & BioRaiz $(\mathbf{g})$ \\
\hline 1 & $30,70 \mathrm{~b}$ & $2,07 \mathrm{c}$ & $26,20 \mathrm{a}$ & $0,73 \mathrm{~b}$ & $0,34 \mathrm{~b}$ & $0,53 \mathrm{~b}$ \\
2 & $37,30 \mathrm{a}$ & $2,68 \mathrm{ab}$ & $26,00 \mathrm{a}$ & $1,36 \mathrm{a}$ & $0,56 \mathrm{a}$ & $0,64 \mathrm{ab}$ \\
3 & $35,70 \mathrm{ab}$ & $2,68 \mathrm{ab}$ & $28,30 \mathrm{a}$ & $1,03 \mathrm{ab}$ & $0,49 \mathrm{ab}$ & $0,73 \mathrm{ab}$ \\
4 & $33,10 \mathrm{ab}$ & $2,50 \mathrm{~b}$ & $26,80 \mathrm{a}$ & $1,26 \mathrm{a}$ & $0,52 \mathrm{a}$ & $0,67 \mathrm{ab}$ \\
5 & $37,60 \mathrm{a}$ & $2,97 \mathrm{a}$ & $27,00 \mathrm{a}$ & $1,36 \mathrm{a}$ & $0,63 \mathrm{a}$ & $0,80 \mathrm{a}$ \\
6 & $36,40 \mathrm{a}$ & $3,02 \mathrm{a}$ & $27,60 \mathrm{a}$ & $1,38 \mathrm{a}$ & $0,59 \mathrm{a}$ & $0,70 \mathrm{ab}$ \\
7 & $32,60 \mathrm{ab}$ & $2,94 \mathrm{a}$ & $26,80 \mathrm{a}$ & $1,14 \mathrm{a}$ & $0,49 \mathrm{ab}$ & $0,74 \mathrm{a}$ \\
\hline $\mathrm{F}$ & $5,03^{* *}$ & $15,46^{* *}$ & $0,30 \mathrm{~ns}$ & $6,34^{* *}$ & $6,04^{* *}$ & $3,18^{* *}$ \\
DMS & 5,07 & 0,36 & 6,22 & 0,40 & 0,17 & 0,21 \\
CV(\%) & 10,73 & 9,8 & 16,95 & 25,02 & 23,96 & 22,67
\end{tabular}

Onde: Médias seguidas pela mesma letra, na coluna, não diferem entre si pelo teste Tukey 5\%. T1 - 100\% solo; T2 - 100\% Plantmax®; T3 - 50\% solo + 50\% Plantmax ${ }^{\circledR} ;$ T4 - 50\% solo + 50\% cama de frango decomposta; T5 - 50\% Plantmax ${ }^{\circledR}+50 \%$ cama de frango decomposta; T6 - $80 \%$ cama de frango decomposta $+10 \%$ solo $+10 \%$ Plantmax $®$ e; T7 - $20 \%$ cama de frango decomposta $+40 \%$ solo $+40 \%$ Plantmax®.

Fonte: Autoras (2016)

O crescimento em altura foi maior em T2 $\quad(100 \% \quad$ Plantmax®), T5 $\quad(50 \%$ Plantmax $\circledR^{-50 \%}$ cama de frango decomposta) e T6 (80\% cama de frango decomposta $+10 \%$ solo $+10 \%$ Plantmax $($ ), atingindo médias de 37,30, 37,60 e 36,40 


\section{REA - Revista de estudos ambientais (Online) v.18, n. 2, p.25-34, jul./dez. 2016}

$\mathrm{cm}$, respectivamente, que foram $17,7,18,3 \mathrm{e}$ $15,6 \%$ superiores às observadas para o tratamento em que se utilizou apenas o solo como substrato (T1), com $30,70 \mathrm{~cm}$. Isso porque as combinações físicas e químicas do Plantmax ${ }^{\circledR}$ e as da cama de frango decomposta melhoraram as condições do substrato, demonstrando que, nem sempre, um substrato representado apenas pelo solo, será capaz de proporcionar os teores necessários de nutrientes que as plantas precisam para seu ótimo crescimento.

Dessa forma, a adição de um substrato que tem como base a matéria orgânica já em fase de liberação de nutrientes pode propiciar a disponibilização desses nutrientes de forma adequada para as plantas. Além disso, também condiciona fisicamente o solo. A matéria orgânica é capaz de reter umidade e disponibilizá-la gradativamente e, manter a adequada porosidade e densidade do solo.

Kratz et al. (2013) também verificaram que o substrato comercial a base de casca de pinus semidecomposta foi adequado para a produção de mudas de Mimosa scabrella. Enquanto, Pereira et al. (2010), Maranho e Paiva (2012) e Delarmelina et al. (2013) observaram a influência positiva da adição de resíduos orgânicos no crescimento em altura de mudas de Tamarindus indica, Physocalymma scaberrimum e Sesbania virgata, respectivamente.

Para o crescimento em diâmetro, as combinações de T5 (50\% Plantmax $®+50 \%$ cama de frango decomposta), T6 (80\% cama de frango decomposta $+10 \%$ solo $+10 \%$ Plantmax $\circledast)$ e T7 (20\% cama de frango decomposta $+40 \%$ solo $+40 \%$ Plantmax $囚$ ), foram as melhores. Elas atingiram médias de $2,97,3,02$ e $2,94 \mathrm{~mm}$, respectivamente, sendo estas, 30,31 e $29 \%$ maiores que as obtidas para as de T1 $(2,07 \mathrm{~mm})$. Vale reforçar que a cama de frango pode disponibilizar nutrientes e melhorar as condições físicas do solo para o crescimento das mudas, tanto em combinação com o solo quanto em combinação com o substrato comercial.

Resultados semelhantes foram observados por Freitas et al. (2010) para Eucalyptus urophylla produzido em $40 \%$ de casca de eucalipto decomposta $+30 \%$ de torta de filtro + fibra de coco, que atingiram médias de $39 \mathrm{~cm}$ de altura e $2,60 \mathrm{~mm}$ de diâmetro; e por Silva, Simões e Silva (2012) que verificaram mudas de $E$. urophylla $\times E$. grandis com $37 \mathrm{~cm}$ de altura e $3,5 \mathrm{~mm}$ de diâmetro em substrato casca de arroz carbonizado e fibra de coco.

Porém, as médias para altura e diâmetro obtidas no presente experimento foram superiores às observadas por Petter et al. (2012) em E. urophylla e E. citriodora produzidos em substrato comercial acrescido Biochar, após 120 dias; por Silva et al. (2014) na produção de E. grandis em substratos orgânicos e por Kratz e Wendling (2013) em E. dunnii produzido em vermiculita, fibra de coco e casca de arroz carbonizada. Portanto, a cama de frango foi mais favorável para a produção de mudas da espécie que estes substratos.

Considerando que, altura e diâmetro são as características morfológicas mais facilmente utilizadas para indicar se uma planta está apta ao plantio no campo, verificou-se que a combinação do solo com substrato comercial e com resíduo orgânico (cama de frango) foi mais eficiente para promover o crescimento adequado das mudas de E. camaldulensis.

O crescimento em altura e em diâmetro podem ter contribuído para a produção de biomassa das mudas de $E$. camaldulensis. Segundo Albuquerque et al. (2009) o acúmulo de fitomassa em folhas, caule e raízes são informações imprescindíveis para se conhecer o crescimento e o desenvolvimento de uma planta e essas informações podem servir como subsídio para compreender suas fenofases.

As menores médias de produção de biomassa foliar foram observadas em T1 ( $100 \%$ solo), com $0,73 \mathrm{~g}$ e em T3 (50\% solo + $50 \%$ Plantmax $囚$ ) com 1,03 g. Os demais tratamentos obtiveram médias consideradas semelhantes. Esses resultados são importantes porque, de acordo com Gomes e Paiva (2006) a massa seca da parte aérea indica a rusticidade de uma muda, sendo que os maiores valores representam mudas mais lignificadas e rústicas, tendo maior aproveitamento em ambientes com condições adversas. Além disso, podem estar relacionados com o fato de a cama de frango poder disponibilizar nutrientes que estão ligados ao processo fotossintético, dessa forma, quanto maior a taxa fotossintética, mais rápido o requerimento das mudas pelos nutrientes e mais rápido se dá o crescimento. 


\section{REA - Revista de estudos ambientais (Online) v.18, n. 2, p.25-34, jul./dez. 2016}

Os tratamentos que proporcionaram as maiores médias para a biomassa do caule foram T2 (100\% Plantmax®), T4 (50\% solo + $50 \%$ cama de frango decomposta), T5 (50\% Plantmax ${ }^{\circledR}+50 \%$ cama de frango decomposta) e T6 $(80 \%$ cama de frango decomposta $+10 \%$ solo $+10 \%$ Plantmax $®$ ). Esses tratamentos proporcionaram médias de $0,56,0,52,0,63$ e 0,59 g, que foram 39 , $34,6,46$ e $42 \%$, respectivamente, superiores às de T1 (100\% solo), com 0,34 g. Portanto, a cama de frango decomposta e o Plantmax ${ }^{\circledR}$ melhoraram as condições de fertilidade do substrato.

Para a produção de biomassa das raízes, T5 $\left(50 \%\right.$ Plantmax ${ }^{\circledR}+50 \%$ cama de frango decomposta), com $0,80 \mathrm{~g}$, e T7 (20\% cama de frango decomposta $+40 \%$ solo + $40 \%$ Plantmax $\circledast$ ), com $0,74 \mathrm{~g}$, foram os melhores, com médias 33,7 e $28 \%$, respectivamente, maiores que as de $\mathrm{T} 1$ (100\% solo), com 0,53 g. Dados que reforçam os obtidos anteriormente.

Resultados semelhantes foram obtidos por Trazzi, Delarmelina e Caldeira (2013) que verificaram que o maior ganho de massa seca nas mudas de Tectona grandis ocorreu nos tratamentos constituídos por cama de frango, assim como para a altura e para o diâmetro e por Silva, Simões e Silva (2012) em mudas de $E$. urophylla x $E$. grandis que atingiram $0,69 \mathrm{~g}$ para massa seca da raiz em substrato com vermiculita, casca de arroz carbonizado e fibra de coco.

De acordo com Gomes e Silva (2004) dificilmente um material puro conseguirá apresentar todas as características adequadas para compor um bom substrato. $O$ que foi verificado também para as mudas de E. camaldulensis, ao utilizar apenas o solo como substrato. Isso se relaciona com as características químicas do solo, mas também com suas características físicas, dessa forma, há a necessidade de combinar o solo com outros compostos para garantir maior crescimento e produção de biomassa nas plantas produzidas.

Portanto, a cama de frango pode ser utilizada para a produção de mudas de $E$. camaldulensis, em viveiro, porque aumenta seu crescimento, o que pode propiciar a obtenção de mudas aptas para o plantio no campo em menor tempo. Isso garante ao produtor, mais mudas em menos tempo, com menos investimentos em substrato e na fertilização do mesmo.

\subsection{Nutrição de mudas de Eucalyptus camaldulensis}

O crescimento das mudas de $E$. camaldulensis em substrato a base de cama de frango decomposta pode ser explicado pela melhoria nutricional que esta é capaz de proporcionar a esse substrato $e$, por consequência, às plantas. No entanto, como se trata de um produto em fase de decomposição, em que os nutrientes estão na forma orgânica e precisam ser mineralizados, esses elementos podem ser disponibilizados de forma gradativa. De acordo com Torres et al. (2011) a cama de frango, se utilizada em quantidades adequadas à cultura, pode ser uma fonte de nutrientes interessante para ser utilizada tanto na produção de mudas quanto na adubação em geral.

Por isso, realizou-se a análise nutricional das mudas de E. camaldulensis para verificar se as concentrações de nutrientes proporcionados pelas combinações de substratos foram favoráveis à espécie (Tabela 3 ).

Não houve diferença entre as concentrações de $\mathrm{N}$, porém, T3 $(50 \%$ solo + $50 \%$ Plantmax $囚)$, T4 (50\% solo $+50 \%$ cama de frango decomposta) e T6 (80\% cama de frango decomposta $+10 \%$ solo $+10 \%$ Plantmax $($ ) apresentaram médias próximas às consideradas adequadas por Higashi, Silveira e Gonçalves (2000), entre 13 e $15 \mathrm{~g}$ $\mathrm{kg}^{-1}$, ao verificaram valores adequados em folhas de Eucalyptus grandis na idade entre 80 e 100 dias. Isso pode estar relacionado com o requerimento da espécie na fase de crescimento ou com o processo de mineralização da cama de frango, que poderia não ter proporcionado, ainda, concentrações de $\mathrm{N}$ suficientes para atingir os valores recomendados na parte aérea. Porém, não houve $\mathrm{o}$ aparecimento de sintomas de deficiência ou limitações no crescimento das mudas de E. camaldulensis.

As maiores médias para as concentrações de $\mathrm{P}$ foram observadas em T4 $(50 \%$ solo $+50 \%$ cama de frango decomposta), enquanto que, nas condições de T1 (100\% solo) verificaram-se as menores concentrações, evidenciando que a adição de cama de frango como componente de substrato melhorou as condições nutricionais para as mudas de $E$. camaldulensis. As menores concentrações de $\mathrm{P}$ nas condições de $\mathrm{T} 1$ também estão 


\section{REA - Revista de estudos ambientais (Online) v.18, n. 2, p.25-34, jul./dez. 2016}

relacionadas com o fato de que, solos típicos de Cerrado estão comumente relacionados com a baixa disponibilidade de $P$ devido às suas características químicas que favorecem a adsorção do elemento (SOUSA; LOBATO, 2003; ZOZ et al., 2009). Porém, em todos os tratamentos observaram-se concentrações acima das recomendadas por Higashi, Silveira e Gonçalves (2000), entre 1,5 e 2,0 g $\mathrm{kg}^{-1}$, principalmente naqueles acrescidos de cama de frango, o que foi importante para o crescimento das mudas de E. camaldulensis nos substratos com cama de frango e com Plantmax $®$, que pode ser explicado pelas funções do elemento nas reações de armazenamento e liberação de energia (TAIZ; ZEIGER, 2004) e as necessidade nutricionais da espécie estudada durante seu crescimento inicial, que pode ter sido superior ao observado por Higashi, Silveira e Gonçalves (2000).

Tabela 3 - Concentrações de macronutrientes $\left(\mathrm{g} \mathrm{kg}^{-1}\right)$ e micronutriente $\left(\mathrm{mg} \mathrm{kg}^{-1}\right)$, nas folhas das mudas de $E$. camaldulensis em diferentes combinações de substratos

\begin{tabular}{llllllll}
\hline Trat. & $\mathbf{N}$ & $\mathbf{P}$ & $\mathbf{K}$ & $\mathbf{C a}$ & $\mathbf{M g}$ & $\mathbf{S}$ & $\mathbf{B}$ \\
\hline T1 & $8,51 \mathrm{a}$ & $6,33 \mathrm{f}$ & $10,60 \mathrm{bc}$ & $0,83 \mathrm{~b}$ & $0,77 \mathrm{bc}$ & $0,78 \mathrm{~cd}$ & $11,95 \mathrm{~b}$ \\
T2 & $9,74 \mathrm{a}$ & $10,77 \mathrm{~d}$ & $11,23 \mathrm{~b}$ & $1,22 \mathrm{ab}$ & $0,84 \mathrm{bc}$ & $0,29 \mathrm{~d}$ & $20,93 \mathrm{a}$ \\
T3 & $11,59 \mathrm{a}$ & $8,54 \mathrm{e}$ & $10,21 \mathrm{c}$ & $1,22 \mathrm{ab}$ & $0,69 \mathrm{c}$ & $0,56 \mathrm{~d}$ & $13,00 \mathrm{~b}$ \\
T4 & $11,87 \mathrm{a}$ & $16,79 \mathrm{a}$ & $12,20 \mathrm{a}$ & $1,09 \mathrm{ab}$ & $1,84 \mathrm{a}$ & $1,97 \mathrm{a}$ & $14,85 \mathrm{~b}$ \\
T5 & $9,69 \mathrm{a}$ & $12,20 \mathrm{c}$ & $8,02 \mathrm{~d}$ & $1,34 \mathrm{a}$ & $1,34 \mathrm{ab}$ & $1,12 \mathrm{bc}$ & $10,06 \mathrm{~b}$ \\
T6 & $11,48 \mathrm{a}$ & $15,09 \mathrm{~b}$ & $10,50 \mathrm{bc}$ & $1,41 \mathrm{a}$ & $1,54 \mathrm{a}$ & $1,62 \mathrm{ab}$ & $15,29 \mathrm{~b}$ \\
T7 & $9,52 \mathrm{a}$ & $10,73 \mathrm{~d}$ & $8,22 \mathrm{~d}$ & $0,83 \mathrm{~b}$ & $1,27 \mathrm{abc}$ & $1,38 \mathrm{~b}$ & $10,32 \mathrm{~b}$ \\
\hline F & $2,57 \mathrm{~ns}$ & $132,46^{* *}$ & $53,90^{* *}$ & $4,20^{* *}$ & $9,01^{* *}$ & $28,13^{* *}$ & $9,94^{* *}$ \\
DMS & 3,61 & 1,40 & 0,93 & 0,50 & 0,64 & 0,51 & 5,33 \\
CV(\%) & 17,42 & 6,10 & 4,58 & 22,12 & 27,18 & 22,85 & 19,31 \\
\hline
\end{tabular}

Onde: Médias seguidas pela mesma letra, na coluna, não diferem entre si pelo teste Tukey 5\%. T1 - 100\% solo; T2 - 100\% Plantmax®; T3 - 50\% solo + 50\% Plantmax $® ;$ T4 - 50\% solo $+50 \%$ cama de frango decomposta; T5 - 50\% Plantmax $®+50 \%$ cama de frango decomposta; T6 - 80\% cama de frango decomposta $+10 \%$ solo $+10 \%$ Plantmax $®$ e; T7 - 20\% cama de frango decomposta $+40 \%$ solo $+40 \%$ Plantmax®.

Fonte: Autoras (2016)

No entanto, os resultados podem indicar que algumas combinações entre os substratos testados podem proporcionar a disponibilização de altos teores de P (Tabela 3), o que pode acarretar em interações negativas entre nutrientes ou ainda, dependendo da espécie, limitações no desenvolvimento da mesma.

A cama de frango e o Plantmax $®$ também aumentaram as concentrações de $\mathrm{K}$ nas condições de T4 $(50 \%$ solo $+50 \%$ cama de frango decomposta), porém, abaixo das recomendadas por Higashi, Silveira e Gonçalves (2000) de 15 a $20 \mathrm{~g} \mathrm{~kg}^{-1}$, o que não parece ter limitado o crescimento das mudas. Esses dados, explicam o crescimento e a produção de biomassa seca nos tratamentos com cama de frango, pois, $\mathrm{K}$ é um elemento essencial ligado às funções como a manutenção do turgor das células, à transpiração da planta e ao processo fotossintético, além disso, é ativador de dezenas de enzimas. As concentrações de $\mathrm{K}$ em T5 (50\% Plantmax ${ }^{\circledR}+50 \%$ cama de frango decomposta) não foram as maiores, porém, as concentrações observadas nas mudas de E. camaldulensis parecem ter sido suficientes para manter o crescimento das mudas, o que pode estar relacionado ao requerimento em $\mathrm{K}$ nos primeiros meses de crescimento ou ainda, uma maior adaptação do E. camaldulensis às condições de baixa fertilidade do que o E. grandis (espécie utilizada no estudo de HIGASHI, SILVEIRA; GONÇALVES, 2000), que foi utilizada na comparação das médias para as concentrações de macronutrientes. De acordo com Freitas et al. (2010) o teor adequado de $\mathrm{K}$ nas mudas no final do ciclo 


\title{
REA - Revista de estudos ambientais (Online) v.18, n. 2, p.25-34, jul./dez. 2016
}

de viveiro é necessário para uma boa rustificação das mudas.

As maiores concentrações de $\mathrm{Ca}$ foram observadas em T5 (50\% Plantmax $®+$ $50 \%$ cama de frango decomposta) e T6 (80\% cama de frango decomposta $+10 \%$ solo + $10 \%$ Plantmax®), porém, abaixo das sugeridas por Higashi, Silveira e Gonçalves (2000) de 8 a $12 \mathrm{~g} \mathrm{~kg}^{-1}$. Esses dados demonstraram que o $E$. camaldulensis é exigente em $\mathrm{Ca}$ em baixas concentrações e que, a combinação de cama de frango com substrato comercial foi eficiente para a disponibilização desse macronutriente. O mesmo foi observado para o Mg, porém, as melhores condições foram as de T4 (50\% solo $+50 \%$ cama de frango decomposta) e de T6 (80\% cama de frango decomposta + $10 \%$ solo + $10 \%$ Plantmax $®)$.

As maiores concentrações de $\mathrm{S}$ foram observadas em T4 $(50 \%$ solo $+50 \%$ cama de frango decomposta). Nesse caso, em T4 (50\% solo $+50 \%$ cama de frango decomposta), T6 (80\% cama de frango decomposta $+10 \%$ solo $+10 \%$ Plantmax $®) e$ T7 $(20 \%$ cama de frango decomposta $+40 \%$ solo $+40 \%$ Plantmax $囚)$ essas concentrações estiveram dentro da faixa recomendada por Higashi, Silveira e Gonçalves (2000), o que favoreceu o crescimento das mudas. Reforçando que a cama de frango, por ser um resíduo orgânico rico em nutrientes, pode ser utilizada na produção de mudas de $E$. camaldulensis.

Para as concentrações de $B$, as plantas em T2 (100\% Plantmax $®)$ foram as que apresentaram as maiores médias, dentro das recomendadas por Higashi, Silveira e Gonçalves (2000). Sabe-se que espécies do gênero Eucalyptus são exigentes em B, porém, durante os primeiros 90 dias de crescimento, as concentrações apresentadas em T5 parecem ter sido suficientes para o $E$. camaldulensis, pois, as mudas não apresentaram sintomas de deficiências ou limitações no crescimento.

Portanto, o maior crescimento para as mudas de E. camaldulensis em T5 (50\% Plantmax $®+50 \%$ cama de frango decomposta) pode ser explicado pelas condições nutricionais, com concentrações de nutrientes mais favoráveis nessa combinação de substratos.

\section{Conclusões}

A cama de frango é um componente orgânico de substrato que pode ser utilizado na produção de mudas de E. camaldulensis, nas proporções de $50 \%$ Plantmax $®+50 \%$ cama de frango decomposta, que melhora as condições nutricionais do substrato, promovendo o adequado crescimento das mudas no viveiro.

A utilização da cama de frango como componente de substrato deve ser realizada com cautela, pois, algumas combinações desta com outros componentes podem proporcionar a disponibilização de altos teores de alguns nutrientes e, consequentemente, acarretar em limitações no crescimento das plantas.

\section{Production of Eucalyptus Seedlings in Different Compositions of Substrates}

\begin{abstract}
The production of seedlings with quality requires the use of techniques and inputs that are compatible with the requirements of the species produced. It was carried out experiment in nursery in order to verify the combination of soil, commercial substrate (Plantmax®) and decomposed poultry litter, more suitable for the production of Eucalyptus camaldulensis seedlings. The seedlings were grown in plastic tubetes with a capacity of $160 \mathrm{~cm}^{3}$ with seeds germinated in sand and vermiculite. When they reached $15 \mathrm{~cm}$, the plants were transplanted to the treatments: $100 \%$ soil; $100 \%$ Plantmax $\AA ; 50 \%$ soil $+50 \%$ Plantmax $\circledast ; 50 \%$ soil + $50 \%$ decomposed poultry litter; Plantmax ${ }^{\circledR}$ 50\% + 50\% decomposed poultry litter; $80 \%$ decomposed poultry litter $+10 \%$ soil $+10 \%$ Plantmax $®$ and; $20 \%$ decomposed poultry litter $+40 \%$ soil $+40 \%$ Plantmax $®$, originating seven treatments, arranged in a randomized design with 10 repetitions. The evaluation of the growth occurred 90 days after transplantation, with the measurement of shoot height, diameter, the leaf biomass, diameter biomass and roots biomass and concentrations of nutrients. The combination of substrates that provided the greatest growth of Eucalyptus camaldulensis seedlings was $50 \%$ Plantmax ${ }^{2}+50 \%$ poultry litter decomposed.
\end{abstract}

Keywords: Eucalyptus camaldulensis. Organic input. Organic matter. Organic substrate. 


\section{REA - Revista de estudos ambientais (Online) v.18, n. 2, p.25-34, jul./dez. 2016}

\section{Referências}

ALBUQUERQUE, F. A.; CASTRO, N. H. A.; BELTRÃO, N. E. M.; LUCENA, A. M. A.; SOUZA, S. M.; FREIRE, M. A. O.; SAMPAIO, L. R. Análise de crescimento inicial do Jatropha curcas em condições de sequeiro. Revista Brasileira de Oleaginosas e Fibrosas, Campina Grande, v.13, n.3, p.99-106, 2009.

BRUGNARA, E. C. Cama de aviário em substratos para mudas de maracujazeiro-amarelo. Revista Brasileira de Agroecologia, Porto Alegre, v.9, n.3, p.21-30, 2014.

DELARMELINA, W. M.; CALDEIRA, M. V. W.; FARIA, J. C. T.; GONÇALVES, E. O. Uso de lodo de esgoto e resíduos orgânicos no crescimento de mudas de Sesbania virgata (Cav.) Pers. Revista Agroambiente, Rio Branco, v.7, n.2, p.184-192, 2013.

DEL QUIQUI, E.M.; MARTINS, S.S.; SHIMIZU, J.Y. Avaliação de espécies e procedências de Eucalyptus spp. para o noroeste do estado do Paraná. Acta Scientarium, Maringá, v.23, n.5, p.1173-1177, 2001.

EMPRESA BRASILEIRA DE PESQUISA AGROPECUÁRIA - EMBRAPA. Serviço Nacional de Levantamento e Conservação de Solos. Manual de métodos de análise do solo. 2. ed. Rio de Janeiro: EMBRAPA, 1997. 212 p.

FERREIRA, M. Escolha de espécies de eucalipto. Piracicaba: IPEF, 1979. 30p. (Circular Técnica, n. 47).

FREITAS, T. A. S.; BARROSO, D. G.; SOUZA, L. S.; CARNEIRO, J. G. A.; PAULINO, G. M. Produção de mudas de eucalipto com substratos para sistema de blocos. Revista Árvore, Viçosa, v.34, n.5, p.761-770, 2010.

GOMES, J. M.; SILVA, A. R. Os substratos e sua influência na qualidade de mudas. In: BARBOSA, J. G.; MARTINEZ, H. E. P.; PEDROSA, M. W.; SEDIYAMA, M. A. N. Nutrição e adubação de plantas cultivadas em substratos. Viçosa: UFV, 2004, p. 190-225.

GOMES, J. M.; PAIVA, H. N. Viveiros florestais: propagação sexuada. Viçosa: UFV, 2006. 116 p.

HIGASHI, E. N.; SILVEIRA, R. L. V. A.; GONÇALVES, A. N. Monitoramento nutricional e fertilização em macro, mini e microjardim clonal de eucaliptos. In: GONÇALVES, J.L.M.; BENEDETTI, V. Nutrição e fertilização florestal. v. 1. Piracicaba: IPEF, 2000, p. 191-218.

KRATZ, D.; WENDLING, I. Produção de mudas de Eucalyptus dunnii em substratos renováveis. Floresta, Curitiba, v.43, n.1, p.125-136, 2013.
KRATZ, D.; WENDLING, I.; NOGUEIRA, A. C.; SOUZA, P. V. D. Utilização de resíduos urbanos e agroflorestais para produção de mudas de Eucalyptus benthamii e Mimosa scabrella. Floresta e Ambiente, Seropédica, v.20, n.4, p.530-537, 2013.

MALAVOLTA, E.; VITTI, G. C.; OLIVEIRA, S. A. Avaliação do estado nutricional das plantas: princípios e aplicações. 2. ed. Piracicaba: POTAFOS, 1997. 319 p.

MARANHO, A. S.; PAIVA, A. V. Produção de mudas de Physocalymma scaberrimum em substratos compostos por diferentes porcentagens de resíduo orgânico de açaí. Floresta, Curitiba, v.42, n.2, p.399-408, 2012.

MORAES NETO, S. P. O eucalipto no Cerrado do DF: plantio puro e sistema agrossilvipastoril, 2008. Artigo em Hypertexto. Disponível em: $<$ http://www.infobibos.com/Artigos/2008_1/eucalipt o/index.htm>. Acesso em: 31 jul. 2015.

OLIVEIRA, L. C.; COSTA, E.; OLIVEIRA SOBRINHO, M. F.; BINOTTI, F. F. S.; MARUYAMA, W. I.; ALVES, A. C. Esterco bovino e fibra de coco na formação de mudas de baruzeiro. Revista de Agricultura Neotropical, Cassilândia, v.1, n.2, p.42-51, 2014.

PEREIRA, P. C,; MELO, B.; FREITAS, R. S.; TOMAZ, M. A.; FREITAS, C. J. P. Mudas de tamarindeiro produzidas em diferentes níveis de matéria orgânica adicionada ao substrato. Revista Verde de Agroecologia e Desenvolvimento Sustentável, Pombal, v.5, n.3, p. 152-159, 2010.

PETTER, F. A.; ANDRADE, F. R.; MARIMON JUNIOR, B. H.; GONÇALVES, L. G.; SCHOOSLER, T. R. Biochar como condicionador de substrato para a produção de mudas de eucalipto. Revista Caatinga, Mossoró, v.25, n.4, p.44-51, 2012

SCHEER, M. B.; CARNEIRO, C.; SANTOS, K. G. Substratos à base de lodo de esgoto compostado na produção de mudas de Parapiptadenia rigida (Benth.) Brenan. Scientia Forestalis, Piracicaba, v. 38, n. 88, p. 637-644, dez. 2010.

SILVA, T. A. F.; TUCCI, C. A. F.; SANTOS, J. Z. L.; BATISTA, I. M. P.; MIRANDA, J. F.; SOUZA, M. M. Calagem e adubação fosfatada para a produção de mudas de Swietenia macrophylla. Floresta, Curitiba, v.41, n.3, p.459-470, 2011.

SILVA, R. B. G.; SIMÕES, D.; SILVA, M. R. Qualidade de mudas clonais de Eucalyptus urophylla $\times$ E. grandis em função do substrato. Revista Brasileira de Engenharia Agrícola e Ambiental, Campina Grande, v.16, n.3, p.297302, 2012. 


\section{REA - Revista de estudos ambientais (Online) v.18, n. 2, p.25-34, jul./dez. 2016}

SILVA, R. F.; EITELWEIN, M. T.; CHERUBIN, M. R.; FABBRIS, C.; WEIRICH, S.; PINHEIRO, R. R. Produção de mudas de Eucalyptus grandis em substratos orgânicos alternativos. Ciência Florestal, Santa Maria, v.24, n.3, p.609-619, 2014.

SOUSA, D. M. G.; LOBATO, E. Adubação fosfatada em solos da região do cerrado. Piracicaba: Potafos, 2003. 16p. (Encarte do Informações Agronômicas, n.102).

SOUZA, M. O. A.; SILVA, J. C.; DELLA LUCIA, R. M.; EVANGELISTA, W. V. Avaliação da madeira de Eucalyptus camaldulensis Dehnh e Eucalyptus urophylla S.T. Blake em ensaios de usinagem, visando à produção moveleira. Revista Árvore, Viçosa, v.33, n.4, p.751-758, 2009.

TAIZ, L.; ZEIGER, E. Fisiologia vegetal. 3. ed Porto Alegre: ARTMED, 2004. 719 p.

TORRES, G. N.; VENDRUSCOLO, M. C.; SANTI, A.; SOARES, V. M.; PEREIRA, P. S. X. Desenvolvimento de mudas de pinhão manso sob diferentes doses de cama de frango no substrato.
Revista Verde, Mossoró, v.6, n.4, p.244-250, 2011.

TRAZZI, P. A.; DELARMELINA, W. M.; CALDEIRA, M. V. W. Concentração e qualidade de nutrientes em mudas de teca produzidas em substratos orgânicos. Ecologia e Nutrição Florestal, Santa Maria, v.2, n.1, p.19-31, 2014.

TUCCI, C. A. F.; SANTOS, J. Z. L.; SILVA JUNIOR, C. H. S.; SOUZA, P. A.; BATISTA, I. M. O.; VENTURIN, N. Desenvolvimento de mudas de Swietenia macrophylla em resposta a nitrogênio, fósforo e potássio. Floresta, Curitiba, v.41, n.3, p.471-490, 2011.

WEINÄRTNER, M. A.; ALDRIGHI, C. F. S.; MEDEIROS, C. A. B. Adubação Orgânica. Pelotas: Embrapa Clima Temperado, 2006. 20p.

ZOZ, T.; LANA, M. C.; STEINER, F.; FRANDOLOSO, J. F.; FEY, R. Influência do $\mathrm{pH}$ do solo e de fertilizantes fosfatados sobre a adsorção de fósforo em Latossolo Vermelho. Synergismus scyentifica, Pato Branco, v.4, n.1, 3p. 2009. 